\title{
Innate immune cells as homeostatic regulators of the hematopoietic niche
}

\author{
María Casanova-Acebes • Noelia A-González • \\ Linnea A. Weiss • Andrés Hidalgo
}

Received: 12 February 2014/Revised: 21 February 2014/ Accepted: 23 February 2014/Published online: 15 March 2014

(c) The Japanese Society of Hematology 2014

\begin{abstract}
Two cellular systems of paramount importance for mammalian physiology, the myeloid and the hematopoietic, have received a great deal of attention in the past decade. Myeloid leukocytes, classically involved in mediating innate immune responses, are now known to regulate other important aspects of the organism's physiology, from development to regulation of metabolic functions. In parallel, many diverse cellular and molecular components have been identified in the bone marrow (BM) that are required for the regulation and lifelong preservation of hematopoietic stem and progenitor cells (HSPC). Since the production of blood and immune elements by these multipotent cells responds to environmental signals, it is not entirely surprising that the hematopoietic niches in which HSPC are located can in turn be regulated by the immune system. We review here recent evidence demonstrating that two components of the innate immune system, macrophages and neutrophils, regulate the function of the hematopoietic niche in ways that may favor both the retention and the release of HSPC from the BM. We propose that the highly migratory nature of neutrophils, the presence of a network of tissue-resident macrophages in the BM and possibly in other tissues, and the superb capacity of these innate immune cells to respond to stress endow them with regulatory functions that are ultimately relayed to the hematopoietic niche.
\end{abstract}

M. Casanova-Acebes · N. A-González · L. A. Weiss ·

A. Hidalgo $(\square)$

Department of Epidemiology, Atherothrombosis and Imaging,

Centro Nacional de Investigaciones Cardiovasculares (CNIC),

Melchor Fernández Almagro 3, 28029 Madrid, Spain

e-mail: ahidalgo@cnic.es
Keywords Hematopoietic niche - Neutrophil · Macrophage $\cdot$ Stem cell mobilization $\cdot$ LXR

\section{Introduction}

The majority of hematopoietic stem and progenitor cells (HSPC) in adult mammals reside within the bone marrow (BM). This localization within ossified structures provides a secure location for this population of cells, which are the source of all blood cellular components during the entire lifespan of the organism. Although the hematopoietic compartment is highly regulated during steady-state conditions to ensure an equilibrated production of the elements required for normal blood functions (oxygenation, hemostasis and immunity), it is during conditions of stress that the regulatory functions of the hematopoietic environment become most prominent. How HSPC are regulated to carry out these functions under steady-state and stress conditions has become the subject of intense research efforts. These efforts continue to uncover new insights into how these and other stem cell populations are regulated throughout life. The definition by Schofield in 1978 of a niche "in which the stem cell is seen in association with other cells which determine its behavior" has provided a useful framework to search not only for cell intrinsic but also environmental factors and cells that regulate the biology of blood stem cells [1].

Many different cell types within the BM are now known to form part of the niche that regulates HSPC, including "stromal" and endothelial cells that are in close proximity and produce factors such as CXCL12 or KitL that act directly on HSPC [2,3]. Other cell types may act indirectly through actions on this proximal stroma; these include cells of the neural system, including sympathetic nerves and 
Schwann cells, and osteocytes residing within the bone [46]. However, the potential regulatory function that cells of the hematopoietic lineage exert on these BM niches has remained largely unexplored. This is particularly paradoxical in the case of immune cells, which are well-known regulators of homeostasis in response to injury or infection. Specifically, cells of the innate immune system respond rapidly to external insults through the production of inflammatory mediators. Even more relevant for this review is the growing appreciation that innate immune cells are not only effectors of inflammation but also part of a "housekeeping" system that preserves the homeostatic functions of many tissues [7, 8]. Whether part of these homeostatic tasks includes regulation of stem cell niches has only recently begun to be explored.

The innate immune system comprises several cell lineages distributed in every organ in the body, including the BM. Among these, macrophages constitutively reside in tissues and are characterized by a phenotypic and a functional specialization in each organ, where they are responsible for the removal of dying cells and cellular byproducts [9]. In contrast, neutrophils are present in the circulation and rapidly extravasate to areas of infection or injury, but are also present in the BM and other tissues in the steady state [10]. In this review we will focus on the recent evidences that have begun to uncover important regulatory functions of macrophages and neutrophils on the hematopoietic niche. We will discuss how some fundamental properties of these cells, namely their widespread distribution among tissues and dynamic phenotypic changes in the case of macrophages, as well as a short life and clearance in the case of neutrophils, are essential to provide additional regulatory mechanisms to the hematopoietic niche. Since there is currently little or no evidence for other innate immune lineages, including dendritic cells and specialized innate lymphoid populations, in the regulation of the hematopoietic niche, they will not be discussed here.

\section{Resident macrophages as regulators of the hematopoietic niche}

\section{Tissue-resident macrophages}

Tissue-resident macrophages are present in the majority of tissues in the body and are extremely heterogeneous [11]. The different tissue-resident macrophages exhibit tissuespecific and even micro anatomical niche-specific functions that only in recent years have come to light [9]. Besides their well-characterized immune functions (e.g., initiation of inflammatory responses or clearance of debris after infection), resident macrophages also exhibit relevant metabolic functions in the organism, such as regulation of insulin sensitivity or lipid content in adipose tissue [12]. However, it is their broad capacity to phagocytose that essentially defines the diverse populations of macrophages including, but not limited to, clearance of apoptotic cells during tissue repair and homeostasis [13], clearance of erythroid nuclei in BM and fetal liver [14], removal of pulmonary surfactant by alveolar macrophages [15], engulfment of senescent erythrocytes by red pulp macrophages [16] and kupffer cells [17], and bone degradation by osteoclasts [18].

The heterogeneity of tissue-resident macrophages is a functional feature that in most cases arises from their developmental origin. Recent elegant studies have uncovered this developmental diversity using fate mapping and genome-wide transcriptome analyses [19-21]. In the adult mouse, tissue-resident macrophages are now classified into two groups on the basis of their origin: one that originates in the yolk sac, before the definitive appearance of hematopoietic stem cells at day 10.5 of embryogenesis, and that is maintained by local proliferation and self-renewal in several tissues in adults; and a second population derived from adult hematopoietic progenitors and circulating monocytes [21-23].

A technical issue when studying tissue macrophages has been the lack of universal markers that allow their identification. Murine tissue macrophages can be identified by the expression of the F4/80 antigen [24]. However, F4/80 expression is not restricted to macrophages and not all tissue macrophages, such as those of the marginal zone of the spleen, alveolar macrophages or osteoclasts, express this marker [25, 26]. Therefore, other markers and genetic signatures have been used to define the different subsets of tissue macrophages [19].

\section{Bone marrow macrophages}

Early ultrastructural analyses of the BM by electron microscopy revealed populations of macrophage-like cells that were abundant and distributed throughout the marrow space [27]. These cells were later confirmed to be macrophages by immunoreactivity with the F4/80 antibody [28]. Although these initial studies already noted intimate contacts between macrophages and various components of the $\mathrm{BM}$, they failed to provide insights into their functions in this organ.

Location in specific areas and physiologic functions define macrophage heterogeneity in the BM, where at least two types of macrophages co-exist. Osteoclasts are multinucleated $\mathrm{F} 4 / 80^{\mathrm{LO} / \mathrm{NEG}}$ macrophages located in contact with the bone surface, where they are in charge of bone resorption [18]. Their location in close proximity with the so-called endosteal niches, which are formed by osteoblasts and are associated with HSPC maintenance [29], together with the finding that they can promote degradation of niche 
components (CXCL12, stem cell factor and osteopontin) to allow mobilization of HSPC during stress or in response to cytokines [30], provided the first hint that BM macrophages might regulate the activity of the hematopoietic niche.

A second population of BM macrophages does express the F4/80 antigen and is maintained by self-renewal independently of adult hematopoiesis [31]. By analyzing the distribution of macrophages in the BM, Chang and collaborators [32] initially described a population of $\mathrm{F} 4 / 80+$ macrophages, which they named "osteomacs", that formed a cellular canopy within the endosteal microenvironment and participated in bone remodeling. More recent studies have characterized these macrophages and showed that they express common myeloid markers including CD11b, CD68 and CD115 (the receptor for M-CSF/Csf1) [33-35].

Niche-trophic functions of BM macrophages

$\mathrm{F} 4 / 80+$ macrophages in the BM act as a support for the hematopoietic niche, since their depletion with clodronateloaded liposomes or by inducing macrophage-specific death in a $C s f 1 r$-suicide gene mouse model results in a marked and rapid mobilization of HSPC into the circulation $[33,34]$. F4/80+ macrophages in the BM also express the sialoadhesin CD169. Depletion of CD169-expressing cells in mice resulted in a similar increase in HSPC in blood [33]. Because the increase of HSPC in blood is generally accepted to occur by reductions in the activity of the hematopoietic niche in the BM, thereby leading to progenitor release into the circulation [36, 37], these studies suggested that specific niche components in the marrow are functionally sustained by macrophages.

Studies over the past decade have contributed to better define the cellular constituents of the hematopoietic niche. Different "stromal" cell types within the BM provide an optimal microenvironment that supports the maintenance of HSC in areas near the endosteum (endosteal niche) and around the vasculature (perivascular niche) (see Fig. 1). These stromal cells include endothelial cells, osteoblasts, reticular cells expressing high levels of CXCL12 (Cxcl12abundant reticular cells, or CAR cells; [38]), and perivascular cells expressing high levels of hematopoietic cytokines (including cells expressing the intermediate filament Nestin or the Leptin receptor; [3, 39]). Histological studies have shown that F4/80+ CD169+ macrophages are found in close proximity to several types of niche cells, including Nestin + cells [33], CAR cells [40] and osteoblasts [32, 34]. Functional studies have shown that depletion of these macrophages causes rapid reductions in the number and/or activity of niche cells; for example, upon macrophage depletion, Nestin + cells rapidly and dramatically downregulate the expression of genes related to HSPC maintenance, including Cxcl12, Kitl, Angptl and Vcaml [33].
Although such transcriptional reductions were not found for osteoblasts, in vitro studies showed that macrophages are instead important for osteoblast development and mineralization, and enhance their secretion of CXCL12 [32, 35], a chemokine that is critical for HSPC maintenance [3]. A complementary confirmation of the importance of macrophages in niche integrity was obtained in experiments in which mice were treated with the granulocytic cytokine G-CSF. This treatment, which cause dramatic reductions in the number and activity of niche cells $[35,37$, 41], also promoted exhaustion of the monocytic/macrophage lineage in the BM [42].

While these studies identified a role for macrophages in maintaining the functional integrity of the hematopoietic niche under steady-state or stress conditions, they have provided little information about how macrophages carry out their niche-trophic functions. Because BM macrophages are localized in the vicinity of niche cells [33, 34, 40], it is conceivable that they establish direct communication by cell-cell contacts, as recently proposed for other niche cells in the BM [4, 43]. However, this possibility requires further exploration. A compatible and more plausible scenario is that factors secreted by macrophages directly regulate the activity of niche cells. This idea is supported by in vitro studies showing that protease-sensitive factors secreted by macrophages enhance the production of CXCL12 by BM stromal cells [33]. The identity of this factor(s) remains unknown but analyses using macrophages deficient in IL-1, IL-10, IGF-1 or TNF $\alpha$ have ruled out a single contribution by any one of these cytokines [33]. Recently, a subset of monocytic/macrophage cells expressing the $\alpha$-smooth muscle actin has been shown to promote the expression of Cxcl12 in perivascular Nestin+ cells through the production of prostaglandin E2 [44]. In addition, activated macrophages can produce catecholamines [45], which have been shown to exert potent modulatory functions on Nestin+ niche cells [39]. Thus, multiple factors produced by macrophages may account for their trophic effects on the hematopoietic niche and this should become an important area of investigation.

The hierarchy of hematopoietic precursors ranges from primitive, self-maintaining stem cells to more committed progenitors, and recent studies have defined distinct niche elements supporting each of these precursors [3]. Although it is unknown whether macrophages may preferentially support niches for different types of progenitors, there is evidence that they are important in the development of erythroid precursors. Red blood cells in the adult are enucleated and are generated in specific niches in fetal liver, red pulp of the spleen and adult bone marrow [46]. These niches are known as "erythroblastic islands", and consist of a macrophage in the center surrounded by erythroid precursors at different stages of development [14] 


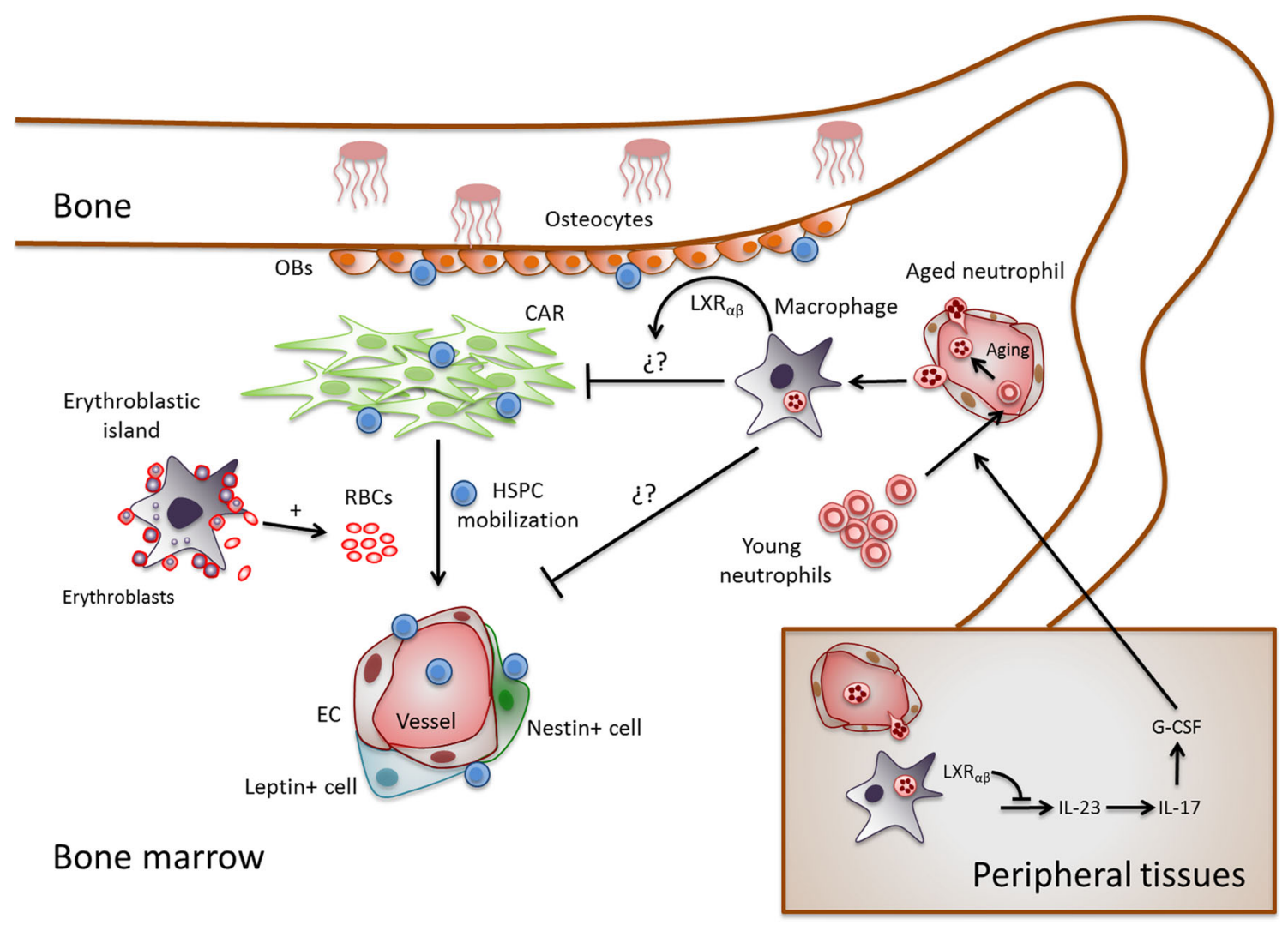

Fig. 1 Local and remote regulation of hematopoietic niches by neutrophils and macrophages. Schematic representation of nichemodulating pathways involving macrophages and neutrophils in BM and peripheral tissues. Niche-trophic and -reducing functions of macrophages can be modulated by phagocytosis of cleared neutrophils both locally (BM) or remotely (in tissues), and involve

(Fig. 1). The macrophages in these erythroblastic islands are in charge of engulfing the nuclei expelled by erythroblast precursors in the last stages of erythroid maturation. Consistent with their central role in erythropoiesis, depletion of CD169+ VCAM-1+ macrophages strongly reduces the numbers of erythroblasts in the BM in the steady state, and significantly delays erythropoietic recovery after hemolytic or myeloablative stress. In this case, the trophic effect of macrophages could be explained at least in part by the production of BMP4 [47]. It remains to be defined whether macrophages exert these effects exclusively through direct effects on the precursors or by actions on a putative "erythroid niche". Importantly, macrophages also support erythropoiesis in a genetic model of polycythemia vera [47], which suggests that macrophages participate in malignant hematopoiesis.

\section{Regulation of the hematopoietic niche by neutrophils}

Neutrophils are innate immune cells committed to protection against bacterial and fungal pathogens [10]. activation of cholesterol-sensing nuclear receptors (LXR). In the $\mathrm{BM}$, macrophages are also required for erythropoiesis. Question marks (?) indicate pathways, target cells or signals that remain to be identified. $O B$ osteoblasts, $E C$ endothelial cells, $C A R$ CXCL12abundant reticular cells

Besides their known participation in the early phases of inflammation, these granulocytes have been recently involved in the homeostasis and function of other immune cells, including the generation of marginal zone B cells in the spleen, NK cells and the proliferation of $\mathrm{T}$ cells [48-50]. In addition, the early immune functions of neutrophils have been recently reported to extend to chronic inflammatory processes including those present in systemic lupus and atherosclerosis, in which they have been shown to sustain the long-term activation of plasmacytoid dendritic cells or the recruitment of activated platelets, respectively [51, 52]. Thus, neutrophils are starting to be viewed with a broader perspective beyond their role in acute inflammation [10].

Neutrophil life and death

Neutrophils are the most abundant myeloid leukocytes and are continuously produced in the BM in large numbers. Approximately $10^{7}$ neutrophils are produced daily in mice [53] by differentiation from common myeloid precursors [54], myeloblasts, promyelocytes and 
myelocytes (for further details refer to [55]). These myeloid progenitors originate non-dividing metamyelocytes, which can further differentiate into banded and, finally, segmented-mature neutrophils [54]. This process takes around 2.3 days in mice [56], and is finely tuned to comply with the organism's demands and storage availability. After maturing, neutrophils remain in the BM for 4-6 more days from where they can be rapidly mobilized into the bloodstream. It is estimated that $90 \%$ of neutrophils reside in the BM while only $1-2 \%$ are found in blood in the steady state [57, 58], and various mechanisms ensure that appropriate numbers of these leukocytes are present in the circulation. The cytokine G-CSF is responsible for promoting not only the differentiation of myeloid precursors into neutrophils but also their release into the bloodstream [35, 58]. Consequently, mice and humans deficient in either G-CSF or its receptor display profound neutropenia [59, 60]. Despite extensive work over the last decade, the mechanisms by which G-CSF induces the release of neutrophils from the BM have not been fully elucidated. Recent advances, however, have revealed that the balance between two chemokines and their cognate receptors are crucial for neutrophil release: the CXCR4-CXCL12 tandem mediates the retention of neutrophils within the $\mathrm{BM}$, whereas CXCL1/CXCL2 signaling through their receptor CXCR2 promotes their release [61, 62].

A key feature when studying neutrophil biology is their short lifespan. In the absence of inflammatory signals they circulate for only a few hours [63], and their half-life in blood has been estimated to be $12.5 \mathrm{~h}$ in mice and up to 5.4 days in humans [56]. Although some of these numbers are still under debate, there is consensus that this short lifespan not only demands their continued production and release from the BM but also generates the need to dispose of very large numbers of neutrophils every day. How neutrophils are cleared from the circulation is still poorly understood, but this process is thought to be important to protect the cardiovascular system from potentially toxic cells. Recent work by us and others revealed that, while in the circulation, neutrophils undergo an "aging" process characterized by elevations in CXCR4 and CD11b and loss of CD62L/L-selectin from their surface, reductions in size, and hypersegmentation of the nucleus $[40,61]$. Changes in these receptors likely account for the increased tropism of aged neutrophils towards the BM, although they also accumulate in the liver and the spleen [40, 64, 65]. Interestingly, detailed analysis of this phenomenon has revealed that the number of total and $\mathrm{CD} 62 \mathrm{~L}^{\mathrm{LO}}$ CXCR $4^{\mathrm{HI}}$ aged neutrophils in blood, as well as their migration to the $\mathrm{BM}$, varies during the course of the day and follow tight circadian patterns $[40,66]$.
Niche regulation by neutrophils

The possibility that neutrophils could influence the activity of the hematopoietic niche was first proposed by Levesque and colleagues a decade ago, while studying the mechanisms of G-CSF- and chemotherapy-induced mobilization of HSPC [67]. Two neutrophil-derived proteases, cathepsin $\mathrm{G}$ and elastase, were found to accumulate in the BM of cytokine-treated mice and to be able to cleave in vitro several receptors and cytokines essential for HSPC retention, including VCAM-1, CXCR4 and CXCL12 [67-69]. Although these observations suggested that neutrophils activated by G-CSF provided a proteolytic environment that altered the HSPC-supportive properties of the BM, further studies using protease-deficient mice discredited the need for neutrophil-derived proteases during HSPC mobilization, as these cells mobilized normally in response to G-CSF in these mice [70]. More recent studies later established that sympathetic neural signaling acting on various cellular components of the niche (e.g., Nestin+ cells, osteoblasts and osteocytes) is critical for this process [4, 39, 71, 72].

Besides mobilizing in response to cytokines or chemotherapeutic agents, HSPC have been known for many years to be present in the circulation under steady-state conditions [73-75]. It is remarkable that the levels of HSPC in the circulation fluctuate during the course of a day and this is caused by parallel circadian changes in the hematopoietic niche elicited by adrenergic signals [37, 40]. Because the clearance of neutrophils from blood and entry into the $\mathrm{BM}$ follow circadian patterns similar to those reported for HSPC [76], we speculated that both phenomena might be causally linked. Indeed, we demonstrated that transfer of purified neutrophils into mice causes a mild but rapid increase in the number of HSPC in blood which correlates with reductions in the number of CXCL12-producing niche cells and total CXCL12 protein levels in the BM. Depletion of circulating neutrophils, in contrast, promotes elevations in the number of niche cells and CXCL12 protein levels, resulting in enhanced retention of HSPC in the BM [40]. These modulating effects on the BM niche occur locally, because the effects are lost in mice in which neutrophils lack tropism to the BM by specific deletion of CXCR4 [61, 62]. As predicted by these findings, depletion of endogenous neutrophils results in a complete loss in the circadian fluctuation of HSPC in blood [40]. Because the sympathetic nervous system influences the steady-state trafficking of leukocytes into the BM [76], it is likely that the two pathways (neutrophil clearance and adrenergic signaling) act in coordination to regulate these time-dependent changes in the hematopoietic niche. These recent findings revealed that the clearance of aged neutrophils inside the BM causes circadian reductions in niche activity and 
explain why the levels of HSPC in blood, like those of neutrophils, undergo circadian variations.

\section{Coordination of neutrophils and macrophages for niche regulation}

How neutrophils modulate the hematopoietic niche? Do they act directly on niche cells or through intermediaries? In vivo imaging of the calvarial BM showed that infiltrating neutrophils do not migrate towards CXCL12-producing niche cells, but instead localize close to resident BM CD169+ macrophages [40]. Although not formally demonstrated at the time, Rankin and colleagues proposed that aged neutrophils are ultimately eliminated by phagocytosis by BM-resident macrophages [64]. Subsequent experiments in mice whose circulatory systems were conjoined by parabiosis demonstrated that neutrophils from one partner end up engulfed by BM macrophages from the other partner [40]. In addition, depletion of BM macrophages completely abolishes the capacity of neutrophils to reduce CXCL12 levels in BM and, remarkably, prevents the circadian fluctuations of HSPC numbers in blood. These findings established a unique coordination between neutrophils and macrophages in the homeostatic control of the hematopoietic niche, and showed that macrophages are necessary intermediaries for the effects of neutrophils on the hematopoietic niche.

Engulfment of apoptotic or senescent cells by macrophages triggers a series of intracellular events that are important to dampen unwanted inflammatory responses [77]. Among these events, activation of LXR receptors (LXR $\alpha$ and $\beta$ ) -most likely by cholesterol derivatives present in the engulfed cells- is involved in switching from a pro- to an anti-inflammatory phenotype in macrophages [78-80], a phenomenon with profound physiological implications as illustrated by the development of chronic inflammation and autoimmunity in mice lacking both LXR receptors [81]. Interestingly, $\operatorname{LXR} \alpha$, but not $\operatorname{LXR} \beta$, is highly expressed in BM macrophages and CXCL12-producing niche cells. Expression of the LXR-target genes Abcal and Mertk in BM macrophages fluctuates following a temporal pattern that parallels neutrophil disappearance from blood and that is sensitive to neutrophil depletion [40], suggesting that phagocytosis of infiltrating neutrophil causes LXR activation in BM macrophages. Notably, treatment with the LXR agonist GW3965 can induce mobilization of HSPC while transfer of neutrophils into LXR-deficient mice fails to reduce CXCL12 levels in BM or to mobilize HSPC [40]. These data demonstrated that cholesterol sensors activated by phagocytosis of neutrophils initiate a program in resident macrophages that prompts reductions in the activity and number of niche cells in the BM, and promote the release of HSPC (Fig. 1). While putative factor(s) produced by these BM macrophages that are responsible for niche regulation remains unidentified, previous in vitro studies found that engulfment of senescent neutrophils by BM-derived macrophages can stimulate the secretion of G-CSF [64], a potent HSPC mobilizing cytokine [36]. We have observed, however, that in vivo blocking of this cytokine fails to disrupt the homeostatic mobilization of HSPC (M.C. and A.H., unpublished data), suggesting that other mechanisms yet to be identified mediate the niche-modulating activity of macrophages.

The requirement of cholesterol-sensing receptors in macrophages in these studies unveiled an intimate connection between niche control and lipid metabolism. An independent study found that hypercholesterolemia disrupts CXCL12 gradients in vivo and triggers mobilization of mature leukocytes and HSPC into blood [82]. In an elegant series of studies, Yvan-Charvet et al. [42, 83] further showed that cholesterol-efflux pathways mediated by the ATP-binding cassette transporters Abca1 and Abcg1 in LysM+ or CD11c + myeloid cells were required to maintain balanced levels of G-CSF in plasma, homeostatic numbers of HSPC, and niche functions of osteoblasts and Nestin+ niche cells. That mechanisms regulating intracellular lipid levels are functionally connected with the hematopoietic niche is puzzling and raises the possibility that cholesterol-sensing mechanisms have evolved as an alarm mechanism that triggers leukocyte and HSPC release into tissues.

\section{Remote regulation and peripheral niches}

Although not fully addressed, there is evidence that elimination of neutrophils in tissues outside the BM may also be important for niche regulation. Studies by Klaus Ley and colleagues showed that impaired clearance of neutrophils in adhesion-deficient mice causes neutrophilia [84]. These studies found that senescent neutrophils are phagocytized by macrophages and dendritic cells present in peripheral tissues, including lung, spleen and mesenteric lymph nodes. In vitro, phagocytosis of senescent neutrophils inhibits the production of IL-23, a cytokine that promotes IL-17 production by subsets of $\mathrm{T}$ cells, which in turn regulates G-CSF production [84]. Interestingly, recent data have shown that this feedback loop is also controlled by LXRs. LXR-deficient mice present impaired elimination of neutrophils, resulting in their accumulation in blood, spleen and liver [85]. Using an in vitro approach, the authors showed that in the absence of LXR signaling the production of IL-23 is elevated in DCs and results in an increase in IL-17 production by $\mathrm{T}$ cells. This dysfunctional IL-23/IL-17/G-CSF axis might contribute to the 
neutrophilic phenotype found in these mice (Fig. 1). In addition, the LXR-target gene Mertk appears to be important in this process since mice deficient in this receptor or its ligand Gas6 also display impaired neutrophil clearance [85]. Thus, processes that resemble those characterized in the BM may control hematopoietic niches remotely from peripheral tissues, by the production of soluble factors such as G-CSF [42].

As indicated earlier, HSPC are also present outside the marrow under steady-state conditions [37, 74, 75]. In addition to blood, extramedullary HSPC can be found in the steady state in liver [86], spleen [87, 88], adipose tissue [89], muscle [90], thoracic duct lymph, lung and kidney [91]. In at least some of these tissues HSPC are associated with vascular structures that resemble to some extent the niches reported in the BM [88]. These progenitors are not static: extramedullary HSPC traffic through peripheral organs over a period of about $36 \mathrm{~h}$, after which they enter draining lymphatics and return to blood and the BM [91]. Thus, there is a continuous trafficking of HSPC among the $\mathrm{BM}$, the circulation and peripheral organs.

Although the physiological function of peripheral HSPC is still uncertain, there is growing evidence that they may participate locally in immune responses. HSPC express TLR2 and TLR4, which sense pathogens and can induce differentiation into myeloid effector cells when activated by agonists [92]. HSPC can also be recruited to inflamed tissues as undifferentiated precursors and expand locally in models of peritonitis, liver or skin injury [93-95]. In at least some cases, HSPC are thought to transit through the spleen for functional specification and differentiation to contribute to atherogenesis and even tumor growth [9698]. Thus, the presence of HSPC in peripheral tissues is functionally important and regulation of their levels may be relevant in a number of immune and inflammatory processes (reviewed in [99, 100]). Whether the persistence of HSPC in extramedullary tissues reflects permanent residence within niche-like structures in these tissues, or reflects continuous transit, it will be important to define the contribution of macrophages (and possibly other innate immune cells that are ubiquitously present in tissues) as regulators of these "peripheral" niches.

\section{Concluding remarks: dynamic regulators of a dynamic niche}

We have summarized here recent findings in a developing field, and as such there are many initial observations that need to be worked out in greater detail. Nonetheless, a key conclusion from these early studies is that hematopoietic niches are regulated by a network of innate immune cells that are extremely dynamic. In the context of resident macrophages, this dynamism refers to their heterogeneity and ability to adapt to a changing environment (for example in conditions of stress, such as anemia or infection) by secreting factors that maintain or restore organ function. The regulation of the BM and the niches within is in this regard, similar to that seen for the metabolic functions in the liver or fat tissues, which are also regulated by tissue-resident macrophages [8]. By acting on HSPC directly, or most likely by regulating the number and transcriptional activity of niche cells, resident macrophages provide trophic signals to the hematopoietic niche as a whole. It will be important in future studies to dissect the nature of such signals and to identify the niche-trophic factors which may prove beneficial in cases of marrow dysfunction or to accelerate recovery from myeloablation.

Another aspect that deserves attention is the identification of the developmental or environmental signals that promote the generation and maintenance of BM macrophages. For example, transcription factors required for the specification of macrophage subsets in the spleen, including SpiC and $\mathrm{LXR} \alpha$, have been identified [16, 101] but have not been reported yet in the case of BM macrophages. Likewise, it will be interesting to determine the environmental signals specific to the BM that promote the generation of these niche-sustaining macrophages, as they may be altered in hematological disorders.

Neutrophils are also extremely dynamic, not only because of the growing appreciation that they can also display varying phenotypes and functions [102] but also because their migratory nature allows them to infiltrate multiple tissues both during inflammation and in the steady state. In the steady state they follow a program of synchronized clearance that, as discussed here for the BM, has relevant functional consequences for niche modulation. During inflammation, the sensitivity of neutrophils to danger signals can lead to dramatic changes in their migratory patterns [65], the consequences of which are likely to have an impact on the hematopoietic niche. Given the massive infiltration of the BM and other organs by aged neutrophils in a rhythmic/circadian fashion, it will be interesting to define the signals directly produced by these cells that may have additional regulatory functions on HSPC or niche components.

We propose that the active regulation of the hematopoietic niche by neutrophils and macrophages endows the niche with the dynamic properties of the innate immune system, and it will be exciting to follow how the mechanistic insights gained from future studies of this dynamism can be used for therapeutic gain by hematologists and stem cell biologists.

Acknowledgments All authors contributed to the writing and editing of this review. We thank Drs. Magdalena Leiva and Vinatha Sreeramkumar for critical comments on the manuscript. This review was supported by grant SAF2012-31142 from the Spanish Ministry of 
Economy and Competitivity (MINECO) and the FP7-People-IRG Program (246655) to A.H. The Centro Nacional de Investigaciones Cardiovasculares is supported by MINECO and the Pro-CNIC Foundation.

\section{References}

1. Schofield R. The relationship between the spleen colony-forming cell and the haemopoietic stem cell. Blood Cells. 1978; 4(1-2):7-25.

2. Ding L, Morrison SJ. Haematopoietic stem cells and early lymphoid progenitors occupy distinct bone marrow niches. Nature. 2013;495(7440):231-5.

3. Ding L, Saunders TL, Enikolopov G, Morrison SJ. Endothelial and perivascular cells maintain haematopoietic stem cells. Nature. 2012;481(7382):457-62.

4. Asada N, Katayama Y, Sato M, Minagawa K, Wakahashi K, Kawano H, et al. Matrix-embedded osteocytes regulate mobilization of hematopoietic stem/progenitor cells. Cell Stem Cell. 2013;12(6):737-47.

5. Mercier FE, Ragu C, Scadden DT. The bone marrow at the crossroads of blood and immunity. Nat Rev Immunol. 2011; 12(1):49-60.

6. Yamazaki S, Ema H, Karlsson G, Yamaguchi T, Miyoshi H, Shioda S, et al. Nonmyelinating Schwann cells maintain hematopoietic stem cell hibernation in the bone marrow niche. Cell. 2011;147(5):1146-58.

7. Nathan C. Neutrophils and immunity: challenges and opportunities. Nat Rev Immunol. 2006;6(3):173-82.

8. Wynn TA, Chawla A, Pollard JW. Macrophage biology in development, homeostasis and disease. Nature. 2013;496(7446): 445-55.

9. Davies LC, Jenkins SJ, Allen JE, Taylor PR. Tissue-resident macrophages. Nat Immunol. 2013;14(10):986-95.

10. Mocsai A. Diverse novel functions of neutrophils in immunity, inflammation, and beyond. J Exp Med. 2013;210(7):1283-99.

11. Hashimoto D, Miller J, Merad M. Dendritic cell and macrophage heterogeneity in vivo. Immunity. 2011;35(3):323-35.

12. Odegaard JI, Chawla A. Mechanisms of macrophage activation in obesity-induced insulin resistance. Nat Clin Pract Endocrinol Metab. 2008;4(11):619-26.

13. Hochreiter-Hufford A, Ravichandran KS. Clearing the dead: apoptotic cell sensing, recognition, engulfment, and digestion. Cold Spring Harb Perspect Biol. 2013;5(1):a008748.

14. Nagata $\mathrm{S}$. Autoimmune diseases caused by defects in clearing dead cells and nuclei expelled from erythroid precursors. Immunol Rev. 2007;220:237-50.

15. Carey B, Trapnell BC. The molecular basis of pulmonary alveolar proteinosis. Clin Immunol. 2010;135(2):223-35.

16. Kohyama M, Ise W, Edelson BT, Wilker PR, Hildner K, Mejia $\mathrm{C}$, et al. Role for Spi-C in the development of red pulp macrophages and splenic iron homeostasis. Nature. 2009;457(7227): 318-21.

17. Klein I, Cornejo JC, Polakos NK, John B, Wuensch SA, Topham DJ, et al. Kupffer cell heterogeneity: functional properties of bone marrow derived and sessile hepatic macrophages. Blood. 2007;110(12):4077-85.

18. Edwards JR, Mundy GR. Advances in osteoclast biology: old findings and new insights from mouse models. Nat Rev Rheumatol. 2011;7(4):235-43.

19. Gautier EL, Shay T, Miller J, Greter M, Jakubzick C, Ivanov S, et al. Gene-expression profiles and transcriptional regulatory pathways that underlie the identity and diversity of mouse tissue macrophages. Nat Immunol. 2012;13(11):1118-28.
20. Ginhoux F, Greter M, Leboeuf M, Nandi S, See P, Gokhan S, et al. Fate mapping analysis reveals that adult microglia derive from primitive macrophages. Science. 2010;330(6005):841-5.

21. Schulz C, Gomez Perdiguero E, Chorro L, Szabo-Rogers H, Cagnard N, Kierdorf K, et al. A lineage of myeloid cells independent of $\mathrm{Myb}$ and hematopoietic stem cells. Science. 2012;336(6077):86-90.

22. Jenkins SJ, Ruckerl D, Cook PC, Jones LH, Finkelman FD, van Rooijen N, et al. Local macrophage proliferation, rather than recruitment from the blood, is a signature of $\mathrm{TH} 2$ inflammation. Science. 2011;332(6035):1284-8.

23. Yona S, Kim KW, Wolf Y, Mildner A, Varol D, Breker M, et al. Fate mapping reveals origins and dynamics of monocytes and tissue macrophages under homeostasis. Immunity. 2013;38(1): 79-91.

24. Hume DA, Robinson AP, MacPherson GG, Gordon S. The mononuclear phagocyte system of the mouse defined by immunohistochemical localization of antigen F4/80. Relationship between macrophages, Langerhans cells, reticular cells, and dendritic cells in lymphoid and hematopoietic organs. J Exp Med. 1983;158(5):1522-36.

25. Gordon S. The macrophage. BioEssays: News Rev Mol Cell Dev Biol. 1995;17(11):977-86.

26. Kraal G. Cells in the marginal zone of the spleen. Int Rev Cytol. 1992;132:31-74.

27. Weiss L. The hematopoietic microenvironment of the bone marrow: an ultrastructural study of the stroma in rats. Anat Rec. 1976;186(2):161-84.

28. Crocker PR, Morris L, Gordon S. Novel cell surface adhesion receptors involved in interactions between stromal macrophages and haematopoietic cells. J Cell Sci Suppl. 1988;9:185-206.

29. Calvi LM, Adams GB, Weibrecht KW, Weber JM, Olson DP, Knight MC, et al. Osteoblastic cells regulate the haematopoietic stem cell niche. Nature. 2003;425(6960):841-6.

30. Kollet O, Dar A, Shivtiel S, Kalinkovich A, Lapid K, Sztainberg Y, et al. Osteoclasts degrade endosteal components and promote mobilization of hematopoietic progenitor cells. Nat Med. 2006;12(6):657-64.

31. Hashimoto D, Chow A, Noizat C, Teo P, Beasley MB, Leboeuf $\mathrm{M}$, et al. Tissue-resident macrophages self-maintain locally throughout adult life with minimal contribution from circulating monocytes. Immunity. 2013;38(4):792-804.

32. Chang MK, Raggatt LJ, Alexander KA, Kuliwaba JS, Fazzalari NL, Schroder K, et al. Osteal tissue macrophages are intercalated throughout human and mouse bone lining tissues and regulate osteoblast function in vitro and in vivo. J Immunol. 2008;181(2):1232-44.

33. Chow A, Lucas D, Hidalgo A, Mendez-Ferrer S, Hashimoto D, Scheiermann C, et al. Bone marrow CD169+ macrophages promote the retention of hematopoietic stem and progenitor cells in the mesenchymal stem cell niche. J Exp Med. 2011; 208(2):261-71.

34. Winkler IG, Sims NA, Pettit AR, Barbier V, Nowlan B, Helwani $\mathrm{F}$, et al. Bone marrow macrophages maintain hematopoietic stem cell (HSC) niches and their depletion mobilizes HSCs. Blood. 2010;116(23):4815-28.

35. Christopher MJ, Rao M, Liu F, Woloszynek JR, Link DC. Expression of the G-CSF receptor in monocytic cells is sufficient to mediate hematopoietic progenitor mobilization by G-CSF in mice. J Exp Med. 2011;208(2):251-60.

36. Levesque JP, Winkler IG. Mobilization of hematopoietic stem cells: state of the art. Curr Opin Organ Transplant. 2008; 13(1):53-8.

37. Mendez-Ferrer S, Lucas D, Battista M, Frenette PS. Haematopoietic stem cell release is regulated by circadian oscillations. Nature. 2008;452(7186):442-7. 
38. Omatsu Y, Sugiyama T, Kohara H, Kondoh G, Fujii N, Kohno $\mathrm{K}$, et al. The essential functions of adipo-osteogenic progenitors as the hematopoietic stem and progenitor cell niche. Immunity. 2010;33(3):387-99.

39. Mendez-Ferrer S, Michurina TV, Ferraro F, Mazloom AR, Macarthur BD, Lira SA, et al. Mesenchymal and haematopoietic stem cells form a unique bone marrow niche. Nature. 2010;466(7308):829-34.

40. Casanova-Acebes M, Pitaval C, Weiss LA, Nombela-Arrieta C, Chevre R, A-González N, et al. Rhythmic modulation of the hematopoietic niche through neutrophil clearance. Cell. 2013;153(5):1025-35.

41. Semerad CL, Christopher MJ, Liu F, Short B, Simmons PJ, Winkler I, et al. G-CSF potently inhibits osteoblast activity and CXCL12 mRNA expression in the bone marrow. Blood. 2005;106(9):3020-7.

42. Westerterp M, Gourion-Arsiquaud S, Murphy AJ, Shih A, Cremers S, Levine RL, et al. Regulation of hematopoietic stem and progenitor cell mobilization by cholesterol efflux pathways. Cell Stem Cell. 2012;11(2):195-206.

43. Gonzalez-Nieto D, Li L, Kohler A, Ghiaur G, Ishikawa E, Sengupta A, et al. Connexin-43 in the osteogenic BM niche regulates its cellular composition and the bidirectional traffic of hematopoietic stem cells and progenitors. Blood. 2012;119(22): 5144-54.

44. Ludin A, Itkin T, Gur-Cohen S, Mildner A, Shezen E, Golan K, et al. Monocytes-macrophages that express alpha-smooth muscle actin preserve primitive hematopoietic cells in the bone marrow. Nat Immunol. 2012;13(11):1072-82.

45. Flierl MA, Rittirsch D, Nadeau BA, Chen AJ, Sarma JV, Zetoune FS, et al. Phagocyte-derived catecholamines enhance acute inflammatory injury. Nature. 2007;449(7163):721-5.

46. Palis J, Segel GB. Developmental biology of erythropoiesis. Blood Rev. 1998;12(2):106-14.

47. Chow A, Huggins M, Ahmed J, Hashimoto D, Lucas D, Kunisaki Y, et al. CD169(+) macrophages provide a niche promoting erythropoiesis under homeostasis and stress. Nat Med. 2013;19(4):429-36.

48. Puga I, Cols M, Barra CM, He B, Cassis L, Gentile M, et al. B cell-helper neutrophils stimulate the diversification and production of immunoglobulin in the marginal zone of the spleen. Nat Immunol. 2012;13(2):170-80.

49. Jaeger BN, Donadieu J, Cognet C, Bernat C, Ordonez-Rueda D, Barlogis V, et al. Neutrophil depletion impairs natural killer cell maturation, function, and homeostasis. J Exp Med. 2012; 209(3):565-80.

50. Pillay J, Kamp VM, van Hoffen E, Visser T, Tak T, Lammers $\mathrm{JW}$, et al. A subset of neutrophils in human systemic inflammation inhibits T cell responses through Mac-1. J Clin Invest. 2012;122(1):327-36.

51. Garcia-Romo GS, Caielli S, Vega B, Connolly J, Allantaz F, Xu $Z$, et al. Netting neutrophils are major inducers of type I IFN production in pediatric systemic lupus erythematosus. Sci Transl Med. 2011;3(73):73ra20

52. Chevre R, Gonzalez-Granado JM, Megens RT, Sreeramkumar V, Silvestre-Roig C, Molina-Sanchez P, et al. High-resolution imaging of intravascular atherogenic inflammation in live mice. Circ Res. 2014;114(5):770-79.

53. Boxio R, Bossenmeyer-Pourie C, Steinckwich N, Dournon C, Nusse O. Mouse bone marrow contains large numbers of functionally competent neutrophils. J Leukoc Biol. 2004;75(4): 604-11.

54. Orkin SH, Zon LI. Hematopoiesis: an evolving paradigm for stem cell biology. Cell. 2008;132(4):631-44.

55. Boll IT, Fuchs G. A kinetic model of granulocytopoiesis. Exp Cell Res. 1970;61(1):147-52.
56. Pillay J, den Braber I, Vrisekoop N, Kwast LM, de Boer RJ, Borghans JA, et al. In vivo labeling with $2 \mathrm{H}_{2} \mathrm{O}$ reveals a human neutrophil lifespan of 5.4 days. Blood. 2010;116(4):625-7.

57. Athens JW, Haab OP, Raab SO, Mauer AM, Ashenbrucker H, Cartwright GE, et al. Leukokinetic studies. IV. The total blood, circulating and marginal granulocyte pools and the granulocyte turnover rate in normal subjects. J Clin Invest. 1961;40:989-95.

58. Semerad CL, Liu F, Gregory AD, Stumpf K, Link DC. G-CSF is an essential regulator of neutrophil trafficking from the bone marrow to the blood. Immunity. 2002;17(4):413-23.

59. Lieschke GJ, Grail D, Hodgson G, Metcalf D, Stanley E, Cheers $\mathrm{C}$, et al. Mice lacking granulocyte colony-stimulating factor have chronic neutropenia, granulocyte and macrophage progenitor cell deficiency, and impaired neutrophil mobilization. Blood. 1994;84(6):1737-46.

60. Liu F, Wu HY, Wesselschmidt R, Kornaga T, Link DC. Impaired production and increased apoptosis of neutrophils in granulocyte colony-stimulating factor receptor-deficient mice. Immunity. 1996;5(5):491-501.

61. Martin C, Burdon PC, Bridger G, Gutierrez-Ramos JC, Williams TJ, Rankin SM. Chemokines acting via CXCR2 and CXCR4 control the release of neutrophils from the bone marrow and their return following senescence. Immunity. 2003;19(4): 583-93.

62. Eash KJ, Means JM, White DW, Link DC. CXCR4 is a key regulator of neutrophil release from the bone marrow under basal and stress granulopoiesis conditions. Blood. 2009;113(19): 4711-9.

63. Summers C, Rankin SM, Condliffe AM, Singh N, Peters AM, Chilvers ER. Neutrophil kinetics in health and disease. Trends Immunol. 2010;31(8):318-24.

64. Furze RC, Rankin SM. The role of the bone marrow in neutrophil clearance under homeostatic conditions in the mouse. FASEB J. 2008;22(9):3111-9.

65. Suratt BT, Young SK, Lieber J, Nick JA, Henson PM, Worthen GS. Neutrophil maturation and activation determine anatomic site of clearance from circulation. Am J Physiol Lung Cell Mol Physiol. 2001;281(4):L913-21.

66. Scheiermann C, Kunisaki Y, Frenette PS. Circadian control of the immune system. Nat Rev Immunol. 2013;13(3):190-8.

67. Levesque JP, Takamatsu Y, Nilsson SK, Haylock DN, Simmons PJ. Vascular cell adhesion molecule-1 (CD106) is cleaved by neutrophil proteases in the bone marrow following hematopoietic progenitor cell mobilization by granulocyte colony-stimulating factor. Blood. 2001;98(5):1289-97.

68. Levesque JP, Hendy J, Takamatsu Y, Williams B, Winkler IG, Simmons PJ. Mobilization by either cyclophosphamide or granulocyte colony-stimulating factor transforms the bone marrow into a highly proteolytic environment. Exp Hematol. 2002;30(5):440-9.

69. Levesque JP, Hendy J, Takamatsu Y, Simmons PJ, Bendall LJ. Disruption of the CXCR4/CXCL12 chemotactic interaction during hematopoietic stem cell mobilization induced by GCSF or cyclophosphamide. J Clin Invest. 2003;111(2):187-96.

70. Levesque JP, Liu F, Simmons PJ, Betsuyaku T, Senior RM, Pham C, et al. Characterization of hematopoietic progenitor mobilization in protease-deficient mice. Blood. 2004;104(1): 65-72.

71. Katayama Y, Battista M, Kao WM, Hidalgo A, Peired AJ, Thomas SA, et al. Signals from the sympathetic nervous system regulate hematopoietic stem cell egress from bone marrow. Cell. 2006;124(2):407-21.

72. Mendez-Ferrer S, Battista M, Frenette PS. Cooperation of beta(2)- and beta(3)-adrenergic receptors in hematopoietic progenitor cell mobilization. Ann N Y Acad Sci. 2010;1192:139-44. 
73. Abkowitz JL, Robinson AE, Kale S, Long MW, Chen J. Mobilization of hematopoietic stem cells during homeostasis and after cytokine exposure. Blood. 2003;102(4):1249-53.

74. Goodman JW, Hodgson GS. Evidence for stem cells in the peripheral blood of mice. Blood. 1962;19:702-14.

75. Wright DE, Wagers AJ, Gulati AP, Johnson FL, Weissman IL. Physiological migration of hematopoietic stem and progenitor cells. Science. 2001;294(5548):1933-6.

76. Scheiermann C, Kunisaki Y, Lucas D, Chow A, Jang JE, Zhang $\mathrm{D}$, et al. Adrenergic nerves govern circadian leukocyte recruitment to tissues. Immunity. 2012;37(2):290-301.

77. Soehnlein O, Lindbom L. Phagocyte partnership during the onset and resolution of inflammation. Nat Rev Immunol. 2010;10(6):427-39.

78. A-Gonzalez N, Castrillo A. Liver X receptors as regulators of macrophage inflammatory and metabolic pathways. Biochim Biophys Acta. 2011;1812(8):982-94.

79. Glass CK, Saijo K. Nuclear receptor transrepression pathways that regulate inflammation in macrophages and T cells. Nat Rev Immunol. 2010;10(5):365-76.

80. Joseph SB, Castrillo A, Laffitte BA, Mangelsdorf DJ, Tontonoz P. Reciprocal regulation of inflammation and lipid metabolism by liver X receptors. Nat Med. 2003;9(2):213-9.

81. A-González N, Bensinger SJ, Hong C, Beceiro S, Bradley MN, Zelcer N, et al. Apoptotic cells promote their own clearance and immune tolerance through activation of the nuclear receptor LXR. Immunity. 2009;31(2):245-58.

82. Gomes AL, Carvalho T, Serpa J, Torre C, Dias S. Hypercholesterolemia promotes bone marrow cell mobilization by perturbing the SDF-1:CXCR4 axis. Blood. 2010;115(19):3886-94.

83. Yvan-Charvet L, Pagler T, Gautier EL, Avagyan S, Siry RL, Han S, et al. ATP-binding cassette transporters and HDL suppress hematopoietic stem cell proliferation. Science. 2010; 328(5986):1689-93.

84. Stark MA, Huo Y, Burcin TL, Morris MA, Olson TS, Ley K. Phagocytosis of apoptotic neutrophils regulates granulopoiesis via IL-23 and IL-17. Immunity. 2005;22(3):285-94.

85. Hong C, Kidani Y, A-González N, Phung T, Ito A, Rong X, et al. Coordinate regulation of neutrophil homeostasis by liver $\mathrm{X}$ receptors in mice. J Clin Invest. 2012;122(1):337-47.

86. Cardier JE, Barbera-Guillem E. Extramedullary hematopoiesis in the adult mouse liver is associated with specific hepatic sinusoidal endothelial cells. Hepatology. 1997;26(1):165-75.

87. Dutta P, Courties G, Wei Y, Leuschner F, Gorbatov R, Robbins $\mathrm{CS}$, et al. Myocardial infarction accelerates atherosclerosis. Nature. 2012;487(7407):325-9.

88. Kiel MJ, Yilmaz OH, Iwashita T, Yilmaz OH, Terhorst C, Morrison SJ. SLAM family receptors distinguish hematopoietic stem and progenitor cells and reveal endothelial niches for stem cells. Cell. 2005;121(7):1109-21.

89. Han J, Koh YJ, Moon HR, Ryoo HG, Cho CH, Kim I, et al. Adipose tissue is an extramedullary reservoir for functional hematopoietic stem and progenitor cells. Blood. 2010; 115(5):957-64.

90. McKinney-Freeman SL, Jackson KA, Camargo FD, Ferrari G, Mavilio F, Goodell MA. Muscle-derived hematopoietic stem cells are hematopoietic in origin. Proc Natl Acad Sci USA. 2002;99(3):1341-6.

91. Massberg S, Schaerli P, Knezevic-Maramica I, Kollnberger M, Tubo N, Moseman EA, et al. Immunosurveillance by hematopoietic progenitor cells trafficking through blood, lymph, and peripheral tissues. Cell. 2007;131(5):994-1008.

92. Nagai Y, Garrett KP, Ohta S, Bahrun U, Kouro T, Akira S, et al. Toll-like receptors on hematopoietic progenitor cells stimulate innate immune system replenishment. Immunity. 2006;24(6): 801-12.

93. Granick JL, Falahee PC, Dahmubed D, Borjesson DL, Miller LS, Simon SI. Staphylococcus aureus recognition by hematopoietic stem and progenitor cells via TLR2/MyD88/PGE2 stimulates granulopoiesis in wounds. Blood. 2013;122(10): 1770-8.

94. Kim MH, Liu W, Borjesson DL, Curry FR, Miller LS, Cheung $\mathrm{AL}$, et al. Dynamics of neutrophil infiltration during cutaneous wound healing and infection using fluorescence imaging. J Invest Dermatol. 2008;128(7):1812-20.

95. Si Y, Tsou CL, Croft K, Charo IF. CCR2 mediates hematopoietic stem and progenitor cell trafficking to sites of inflammation in mice. J Clin Invest. 2010;120(4):1192-203.

96. Cortez-Retamozo V, Etzrodt M, Newton A, Rauch PJ, Chudnovskiy A, Berger $\mathrm{C}$, et al. Origins of tumor-associated macrophages and neutrophils. Proc Natl Acad Sci USA. 2012;109(7):2491-6.

97. Leuschner F, Rauch PJ, Ueno T, Gorbatov R, Marinelli B, Lee WW, et al. Rapid monocyte kinetics in acute myocardial infarction are sustained by extramedullary monocytopoiesis. J Exp Med. 2012;209(1):123-37.

98. Robbins CS, Chudnovskiy A, Rauch PJ, Figueiredo JL, Iwamoto Y, Gorbatov R, et al. Extramedullary hematopoiesis generates Ly-6C(high) monocytes that infiltrate atherosclerotic lesions. Circulation. 2012;125(2):364-74.

99. Granick JL, Simon SI, Borjesson DL. Hematopoietic stem and progenitor cells as effectors in innate immunity. Bone Marrow Res. 2012;2012:165107.

100. Schulz C, Von Andrian UH, Massberg S. Trafficking of murine hematopoietic stem and progenitor cells in health and vascular disease. Microcirculation. 2009;16(6):497-507.

101. A-González N, Guillen JA, Gallardo G, Diaz M, de la Rosa JV, Hernandez IH, et al. The nuclear receptor LXRalpha controls the functional specialization of splenic macrophages. Nat Immunol. 2013;14(8):831-9.

102. Beyrau M, Bodkin JV, Nourshargh S. Neutrophil heterogeneity in health and disease: a revitalized avenue in inflammation and immunity. Open Biol. 2012;2(11):120134. 